\title{
STEADY STATE VIBRATION TESTS OF A SIX-STOREY REINFORCED CONCRETE BUILDING
}

\author{
A. M. Reay* and R. Shepherd**
}

\section{Synopsis}

Five modes of vibration of a six-storey reinforced concrete building were excited by steady-state resonance testing. Good correlation between predicted and measured frequencies was obtained.

In the lateral translation tests, two translation modes and the vibration of the roof as a free-free beam were excited. Damping measured in the fundamental mode was $4.1 \%$ critical and the average contribution of foundation compliance to the top-storey deflection was $32 \%$. Damping in the second translation mode was $6.6 \%$ ana of the free-free beam vibration, $3.6 \%$.

The first torsional mode of the building was excited, and for an eight-fold increase in excitation force, the natural frequency reduced by $1.2 \%$, indicating a slight degree of nonlinearity in the response. Damping in this mode was $6.9 \%$, no change being noted for the eight-fold force increase.

In the longitudinal direction, two modes were excited, the first torsional mode and the first longitudinal translation mode. Properties of the former were similar to those determined from the torsional response test. Damping in the translation mode was $10.1 \%$ and the foundation compliance contributed $24 \%$ of the topstorey deflection.

\section{Introduction}

The importance of accurate prediction of the dynamic elastic characteristics of a proposed building is well recognised by designers in earthquake prone areas (1). Nevertheless the idealisations by which a prototype building is transformed into a model amenable to mathematical analysis are rarely questioned despite the availability of relatively few studies of the correlation between predicted and measured dynamic properties of full scale structures. Consequently the opportunity to investigate the steady state small amplitude vibration response of tall buildings in Christchurch has resulted in several such structures being tested. In this paper the investigation carried out in the six-storey Zoology building at the University of Canterbury is described and the correlation between measured and predicted behaviour is presented.

The building is inherently rigid since

* Assistant Engineer, Hardie and Anderson, Consulting Engineers, Christchurch.

* Reader in Civil Engineering, University of Canterbury, Christchurch, New Zealand. this solution was considered by the designers, the New Zealand Ministry of Works, to be the most economical and suitable for a science building of the proposed height.

When tested the structure of the building was complete, and most of the upper floor partition walls and ceiling panels had been erected. Benches and cupboards, while not generally installed, were stored in the rooms. The two lifts were installed but were not operational. Stairs at both ends of the building were complete.

The principal vibration tests, extending over a two-month period, were designed to determine the normal mode properties of the structure, including the consideration of the effects of a varying excitation force on the response. Soil foundation interation was measured and the damping characteristics of the whole building were determined.

\section{The Structure}

The Zoology Building is a six-storey reinforced concrete frame and shear wall structure with a penthouse on the roof at the north end containing the lift machinery and heating and ventilating plant. The building is part of a science complex and is linked to the remainder of the complex by an elevated steel-framed corridor located on the north end at the firstfloor level. The corridor structure is selfsupporting and connected to the Zoology Build. ing by a sliding bolted joint, to ensure that the dynamic response of this building is not modified by a rigid connection to another structure.

A general view of the building is shown in Figure 1 and the overall dimensions and standard structural details of the frames, walls, floors and foundations are presented in Figure 2 .

The principal vertical load supporting elements are the frames, spaced at 9:0" centres, the transverse shear walls taking only the vertical load of the frames they replace. The lateral loading in the transverse (east-west) direction is resisted primarily by the two major transverse shear walls towards the ends of the structure, the load being distributed by in-plane beam action of the floor slabs. The central shear wall extends only from the foundations to the first-floor level, and the frames, although more numerous, are many times more flexible than the shear walls and contribute very Iittle to the total lateral stiffness. Lateral loading in the longitudinal (north-south) direction is resisted by the exterior wall system shown in 
Figure 2.

The reinforced concrete frames contain columns 27 inches deep and 15 inches wide at foundation level and 24 inches deep and 13 inches wide from the ground floor to roof level. The columns are integrated with the exterior wall and are reinforced with an average of 1.8 percent of deformed mild steel bars. Beams, 30 inches deep and 12 inches wide, were cast with the floor slab to form "T" beams of 40 feet span. In general, the beams are reinforced with three 1 inch and three $1 \frac{1}{4}$ inch deformed bars at the columns and six 1 inch deformed bars at mid span. The transverse shear walls and exterior walls are nominally reinforced with additional trimmer bars around all openings.

Secondary reinforced concrete walls, such as those completing the 1 ift shaft against shear wall 3 and several minor walls extending only over one storey, were isolated from the floors and other structural walls by the provision of soft packings at the junctions, together with dowel bars embedded in slack fit sockets.

Cast insitu reinforced concrete stairs are provided at each end of the structure. In both cases the flights are cast clear of shear walls and are designed to span from landing to floor slabs, ensuring that the stress pattern in the shear walls will not be affected by the stair flights.

All suspended slab floors are $5 \frac{1}{2}$ inch thick reinforced concrete. The main roof is of similar construction to the floors but has a structural thickness of only $4 \frac{1}{2}$ inches, with 2 inch precast paving slabs over the exposed roof area to protect the raterproofing membrane. The ground-floor slab, 6 inches thick and nominally reinforced with steel mesh, is cast on consolidated shingle fill.

A11 major structural elements are of cast insitu concrete, the only precast elements being the exposed aggregate exterior facing panels (which were used as permanent shuttering), the precast facing columns at each end of the building and minor architectural items such as the stair treads and solar screens.

The average twenty-eight day compression strength of the concrete in the shear walls and frames was $5,550 \mathrm{p} . \mathrm{s} . \mathrm{i}$. with a range of values from 4,800 to 6,700 p.s.i. as determined from standard cylinder compression tests.

The strip footing foundation system extenas seven feet below natural ground level to a layer of loose sandy gravel. This loose sandy gravel is hundreds of feet thick with occasional thin layers of sand and is a typical section of the fluvial, marine and estuarine deposits of the Canterbury Plains.

Bearing pressures based on the area of strip footings were calculated as $4 \mathrm{kips} / \mathrm{sq}$. ft at the time of testing.

\section{Vibration Exciter and Measuring Equipment}

A unidirectional sinusoidal vibration exciter utilising counter balanced masses rotating about a horizontal axis was used to shake the building.

Displacement meters were used to measure the horizontal and vertical motion of the building, the signals from these instruments being recorded simultaneously on an oscillogram.

Details of the exciter and meters have been published previously $(2)$.

\section{Testing Procedure}

Preliminary tests were undertaken to determine approximate normal mode properiies to the Zoology Building. The vibration exciter was located centrally on the roof of the Zoology Building with the axis of the machine parallel to the longitudinal axis of the building. The exciter was run steadily through a frequency range of 2 to 13 cycles per second, and the amplitude response at three points along the roof (the centre and north and south ends) was continuously recorded. Approximate normal mode shapes and frequencies were derived from these results and were used as a basis for the positioning of the exciter in the subsequent tests.

The principal tests on the Zoology Building were divided into three series, each being designed to emphasise a particular response characteristic of the building by the selected location and orientation of the exciter for that series. The three series determined the response of the structure in lateral translation, longitudinal translation and torsion.

The procedure used for each of these series involved, initially, determining the displacement response of the roof, fourth, and second floors horizontally, and the ground, horizontally and vertically, on line with the centre of action of the exciter. Displacements were recorded at close intervals throughout the frequency range applicable to the series under consideration, displacement response curves were plotted and natural frequencies of the various modes excited were determined. The normal mode shapes of these modes were then determined by recording the response at points throughout the structure to excitation at a minimum of five frequencies close to the natural frequency of each mode. Four displacement meters, three horizontal and one vertical, were used to determine the mode shapes, whilst the fourth horizontal meter was used to repeatedly record the response of the roof at the exciter, as a check on the response of the structure over the period of the test series.

The arrangement of the equipment for these tests required five operators. The vibration exciter, associated control and frequency measuring system were operated from within a tent on the roof. The oscilloscript recorders were installed in the ground floor laboratory at the south end, the test being controlled from this location. In addition, three separate locations of the three mobile horizontal displacement meters required the constant attendance of personnel at each instrument to adjust the instruments as necessary. The vertical displacement meter was always positioned with one of the horizontal displacement meters enabling the one operator to control both, and the fourth horizontal displacement meter and associated dynamic strain bridge was operated by the technician controlling the vibration exciter.

Communication between the five personnel was by field telephones 1 inked by wires run in conjunction with the coaxial cables and power 
96

cables between the displacement pick-up stations and the oscilloscript recorders. The telephone system was used principally for instructions concerning the location of displacement meters and speed of the vibration exciter between the four satellite operators and the test controller operating the oscilloscript recorders.

The procedure adopted when recording a set of displacements at a particular frequency involved waiting until the exciter was running steadily at this frequency for at least one minute, and then recording four to eight oscillations from the five displacement pick ups and the timing pulse from the exciter simultaneously on the oscilloscripts. The period of the exciter was recorded beside these displacements together with the amplifier settings and the temperature of each displacement pick-up.

All testing was restricted to late evening or early morning to avoid conflicting with the contractors and to ensure that the voltage of the power supply remained steady. Calm weather conditions were a requirement of the testing and these were generally only obtainable at night or early morning.

\section{Lateral Translation of the Zoology Building}

The vibration exciter was located over the centre of the frame on the line of Shear Wall 2 for the lateral translation test series.

Displacement response of the roof, fifth, third, second, first and ground floors from 2 c.p.s. to 17 c.p.s. are shown in Figure 3 . The vertical displacement amplitude was measured 6 inches inside the face of the exterior concrete wall on the north side. The displacement amplitude of vibration is plotted in units of an inch, with a force level standard of 1,000 c.p.s. That is, the displacement is that due to an excitation force equal to the force generated by the exciter at 1,000 c.p.s. The true nature of the excitation force is such that it increases with the square of the frequency of the vibration exciter, whereas the amplitude response curve should felate the displacement at a constant amplitude of excitation force. The principle of expressing the displacement amplitude in terms of the equivalent amplitude due to a force generated by the exciter at 1,000 c.p.s. enables the majority of the results to be plotted without further factoring, and expresses the displacement amplitude as a function of a constant excitation force and varying excitation frequency. This method of presentation of displacement response curves is used throughout this study.

Referring again to Figure 3, it can be seen that the first and second translation modes were excited. The first mode of the roof slab vibrating as a free-free beam, was also excited, the natural frequency of the roof being close to that of the second trans. lation mode. The first translation mode frequency was 3.01 c.p.s. and the second 11.34 c.p.s., the ratio of these two mode rrequencies being 3.8 , as compared with the ratio of 3.0 for a uniform shear building. This high ratio is probabiy due in part to the soil-foundation interaction. For all levels in the structure, the first translation mode response curves peak at the same frequency, and the form of alj these curves is the same.

The experimental and theoretical mode shapes for the first lateral translation mode are shown in Figure 4. The theoretical mode shape and frequency were derived using the stiffness matrix, matrix iteration approach (3) both a rigid and a flexible(t) base condition being considered. It can be seen that the structure is deforming principally as a shear building would, together with a base rotation and translation due to the flexible foundation conditions. The experimental mode shape comvares well with the predicted mode shape which includes the flexible base condition, with the exception of the effects of in-plane floor and roof flexibility, which significantly modify the response around the centre of the building. The theoretical fundamental mode frequency is slightly higher than the experimental mode frequency due to the additional restraint in the theoretical analysis provided by rigid floors. Basing the structure on a rigid foundation would increase the theoretical fundamental frequency to $3.52 \mathrm{c.p} . \mathrm{s} . \mathrm{s}$, an increase of $16.5 \%$.

The second lateral translation mode is plotted in Figure 5. The experimental mode shape, recorded at an excitation frequency of 11.34 c.p.s. , was modified not only by the flexibility of the floor slabs, as in the case of the first translation mode, but also by the response of the floor and roof slabs vibrating as free-free beams, the natural frequency of this in-plane vibration being 9.43 c.p.s. Experimental values for the frequency and damping of the interacting modes of the freefree beam vibration and the second translation moder were determined by utilising a response separation technique(5). The theoretical second translation mode frequency of $10.7 \mathrm{c} . \mathrm{p} . \mathrm{s}$. is significantly less than the experimental frequency of $11.34 \mathrm{cop} . \mathrm{s}$. particularly if the additional degree of freedom associated with the in-plane floor flexibility is considered. The principal reason for the difference is that the relative degree of foundation trans. lation was many times as great for the theoretically determined mode shape as for the mode shape determined in the field. Theoretical values of the foundation flexibility used in the prediction of the normal mode properties were derived from the mode shape and frequency of the first translation mode, the effect of the inertia of the soil mass associated with the motion being included in the coefficients describing the foundation flexibility, or, more correctly, pseudo-foundation flexibility. The effect of the soil inertia on the pseudofoundation flexibility depends on both the size of the in-phase soil mass, and the frequency of the motion, and thus the accuracy of modelling the foundation flexibility for one normal mode on properties derived from another depends on the effect of the soil inertia in relation to the actual soil stiffness, and on the shape of the particular mode.

The mode in which the floor and roof vibrate as a free-free beam is shown in Figure 6. The natural frequency of $9.5 \mathrm{c} . \mathrm{p} . \mathrm{s}$. compares well with the theoretical frequency of 9.3 c.p.s. derived from the expression for the natural frequency fi of a uniform free-free beam $(6)$, namely:

$$
f=3.56 \cdot \sqrt{\frac{E I}{M I^{3}}}
$$


where $M=$ total mass of floor slab

$$
\begin{aligned}
& L=\text { length of floor slab } \\
& I=\text { second moment of area of floor slab } \\
& E=\text { Young's modulus }
\end{aligned}
$$

The formula was applied to a floor slab stiffened at the edges by exterior wall panels。

Additional tests were undertaken to determine the effect of the position of the two passenger Iifts on the response in the first translation mode. Amplitude response curves were determined for a frequency range of 2.0 to $5.0 \mathrm{c.p} . \mathrm{s}$. for response of the north end and middle of the roof, with both the lifts at the bottom and top of the lift shaft, but no difference, either in natural frequency and more particularly in the damping, could be discerned within the accuracy of the results.

Throughout the lateral translation test series, one horizontal displacement meter was maintained on the roof to monitor continuously the displacement at this point so that any change in the response characteristics of the structure could be determined. Unlike some reported steady vibration tests $(7)$, no change was observed in the response considering both the effect of a long period of vibration on the structure and the effect of recording the response at an increasing or decreasing frequency of excitation. However, the force amplitude used in the reported tests in which variations were noted was generally greater than those used by the authors.

\section{Torsion of the Zoology Building}

The exciter was positioned 9 feet to the south of shear wall.3, centrally across the roof, with the axis of the exciter along the north-south direction.

Initially, the response of the roof at both the middle and south ends, and the north end of the third fllor was determined for eccentric weight moments of 12.5 and $100 \mathrm{ft} .1 \mathrm{bs}$, the results being presented in Figure?.

The effect of the eight-fold force increase (from 270 lbs to 2150 lbs) on the first torsional mode is clearly indicated in the response curves for the displacement of the roof at the north end. The natural frequency of this mode is reduced by $1.1 \%$ under the higher loading condition, which represents a decrease in the stiffness of the building of $2.2 \%$. No change in the damping characteristics were detected. The decrease in stiffness with increasing force represents a slight degree of non-linearity and is typical of the softening spring characteristic of many structures.

The recorded response of the roof, third and ground floor at the north end for an eccentric weight moment of $12.5 \mathrm{ft} .1 \mathrm{bs}$ is plotted in Figure 8. Both the first translation and first torsional modes were excited. The two modes, having close natural frequencies, interfered to a significant extent necessitating separation by the technique previously mentioned $(5)$, in order to determine the normal mode frequencies and damping values. The response separation technique was applied to the response curves recorded at both ends of the roof, similar values of damping and response being determined from each of the curves.
The theoretical and experimental mode shapes of the first torsional mode are presented in Figure 9. The natural frequency of the rirst torsional mode of the rigid based structure was 4.9 c.p.s., which is $19 \%$ higher than the natural frequency of the equivalent structure on a flexible base of $4.11 \mathrm{c} \cdot \mathrm{p}$.s., the foundation flexibility coefficients of the theoretical model being determined from the first translational mode shape. Experimental and theoretical mode frequencies (flexible base) are in close agreement and whilst the actual structure would be more flexible due to the in-plane floor flexibility, this would be compensated for by an increase in the stiffness due to the torsional rigidity of the structure, an effect which was neglected in the theoretical analysis. The recorded horizontal and vertical foundation displacements were, on the average, similar to those predicted by the theoretical analysis. Differences could be expected due to the differing pressure distributions on the soil between that of the first torsional mode and that of the rirst translation mode, from which the theoretical properties were derived.

Torsional stiffness of the structure will also reduce the rotational response of the foundations if the rotation at one end is opposite to that at the other end of the building.

\section{Longitudinal Translation of the Zoology Building}

The exciter was located centrally at the south end of the structure, with the reaction arms connected to the clamp over the parapet at this end and the axis of the exciter in the east-west direction. A frequency range from $2.8 \mathrm{c} . \mathrm{p}_{0} \mathrm{~s}$ o to $7.0 \mathrm{c} \cdot \mathrm{p} . \mathrm{s}$. with an eccentric weight moment of $12.5 \mathrm{ft} .1 \mathrm{bs}$. was used initially to excite the building. The displacement of the roof, fourth, second and ground floors is shown in Figure 10. It can be seen from this graph that there is an appreciable response from the first torsional mode at $4.15 \mathrm{c} . \mathrm{p} . \mathrm{s}$., indicating a degree of asymmetry about the longitudinal axis of the building and foundation system. The first longitudinal translation response was excited at 4.93 c.p.s., a frequency close to that of the first torsional mode which resulted in considerable interference between these two modes. Both modes were recorded with the axis of the displacement meters in the north-south direction but different relative magnitudes of these two modes were recorded at the various levels due to the positioning of the displacement meters at varying distances from the longitudinal axis of the building. This resulted in variations in the recorded response of the first torsional mode.

All four horizontal response curves of Figure 10 were separated using the method developed for this purpose $(5)$. A comparison of the derived properties of the equivalent simple resonators presented in Table 1 indicates that the results of the four response curves are consistent, even though there were marked variations in the proportion of the torsional response recorded. Also, the average values of the natural frequency of $4.15 \mathrm{c} . \mathrm{p} . \mathrm{s}$. and $6.8 \%$ damping of the s imple resonator representing the first torsional mode compare well with the values of 4.14 c.p.s. and $6.9 \%$ damping determined by separating the first translation and first torsional mode responses from the torsional response of the structure. 
The theoretical and experimental mode shapes of the first longitudinal mode are plotted in Figure 11. The foundation flexibility of the theoretical solution was derived from the experimental mode shape of the first longitudinal mode. Close agreement exists between the displaced shapes, both indicating deformations typical of a shear type building. A discrepancy of $6 \%$ between the theoretical and experiment al natural frequencies is reasonable considering the assumptions made in determining the lateral flexibility matrix of the exterior walled frames. The soil deformations contributed $27 \%$ of the roof deflection, $14 \%$ being due to base translation and $13 \%$ due to base rotation.

The movement detected on the elevated corridor connected to the Zoology Building was less than $10 \%$ of that recorded at the first floor level, validating the assumption that the Zoology Building was structurally isolated from the remainder of the complex.

\section{Damping of the Zoology Building}

The values of damping of the various modes of the Zoology Building as determined from the response curves are listed in Table 2. Also listed are the resonant frequency and the excitation force amplitude at resonance.

The variation in excitation force within the range of these tests appears to have little or no significant effect on the level of the damping on the structure.

The second translation mode has $50 \%$ more damping than the first translation mode. Considering the damping to consist of both "absolute" and "relative" dashpots assists in the formulation of an explanation for this variation. If the damping is of a purely viscous type and consists entirely of relative dashpots (dashpots connecting adjacent floors only), the amount of damping in the second mode would be several times that of the first mode, whilst if the damping consisted entirely of absolute dashpots (dashpots connecting floors to the base only), a marked reduction of the damping in the second mode would be expected. Thus, the 50\% increase in damping indicates that both types are probably present. Another consideration is that there will also be some coulomb type damping present and by definition this damping is independent of frequency.

The first longitudinal mode has a particularly high damping at $10 \%$ critical and there are several possible explanations for this high value. Firstly, the exterior walls were cast against the precast panels with a layer of bitumen on the panels preventing bond, the panels being fixed by several dowel bars so movement between the wall and these panels could result in higher damping in the longitudinal direction. This would not, however, be expected to cause large increases in damping due to the small degree of deformation expected in the wall. Secondly, friction in the sliding bolted connection to the elevated passageway could have contributed to the damping. A large phase difference between the motion at the first floor of the building and the motion of the passageway was recorded but with the amplitude of the passageway vibrations being less than $10 \%$ of that of the first floor of the structure, the friction forces at the joint would be sma11. Thirdly, the damping due to soil-foundation interaction should be taken into account. Vibration energy is dissipated within the foundation medium by conversion of the kinetic energy into heat energy, as is tho case generally within the structure of the ouilding, and also by radiation of energy waves into the surrounding medium. This latter form of energy dissipation is dependent on the length of the structure in relation to the natural wave length of the soil, and would be expected to be particularly significant in a long structure with a high degree of soilfoundation interaction. Thus, damping from this source may be expected to increase when the longitudinal motion of a structure, such as the Zoology Building, is considered in relation to the transverse motion, there being a ratio of length to width of five to one in the case examined.

Foundation compliance is probably responsible for the generally high levels of damping recorded in this test of the Zoology Building in relation to those in Reference ? (which were generally around $2 \%$ for a similar structure) except that foundation compliance was negligible in this earlier investigation. It is also significant that the vibration of the roof slab as a free-free beam contains the least response contribution from soil-foundation interaction and is also damped to the least extent of all the normal modes recorded for the zoology Building.

\section{Theoretical Analysis-Particular Considerations}

As stated previously, the theoretical mode shapes and frequencies were derived using the stiffness matrix, matrix iteration approach, ( 3 and 4 ).

Particular aspects of the theoretical analyses are described in this section.

The resistance to transverse lateral forces is provided by the frames and shear walls. Being structurally isolated, the concrete walls of the lift shaft contributed only mass and not lateral resistance to the building. In considering the shear walls, walls 1 and 3 were treated as identical with differing base flexibilities where as wall 2 was neglected as it terminated at first-floor level.

The resistance to the longitudinal lateral loads is provided by the pierced shear walls forming the exterior facing of the building. The lateral flexibility matrix for these walls was derived as described above for a walled frame with a modification to the joint size. Muto's(8) derivation of joint size is based on a walled frame of constant member thickness, whereas columns of the walled frames of the Zoology Building have flanges. To compensate for the variation in thickness the clear beam length was increased by only one-eighth of the depth at each end and the clear column lengtr. made identical to the centre line length.

The precast concrete facing panels on these frames were considered as monolithic with them, having been used as permanent formwork. The mass of the building was determined from the dead weight of the structure including the facing panels and roof paving slabs, and a live load of $201 \mathrm{bs} / \mathrm{sq}$. ft to include the weightof the furniture, partitions and ceiling 
and floor finishes. The mass of the plant and lift machinery was included in the mass of the roof.

The building was idealised as an eightstorey lumped mass system, the underside of the foundations being represented as storey level 1 and the cuncrete roof as storey level 8. The bottom storey in the idealised building represented the translational flexibility of the foundation material。 Floors and roof elements of the structure were normally considered to be rigid in their own plane.

\section{Foundation Compliance}

A significant aspect of the lateral load characteristics of the building tested is the flexibility provided by the ground. This is summarised in Table 3.

The rotation of the base of the structure was determined from the vertical displacements recorded on each side or on each end of the building and flexibility coefficients, relating moments and forces with rotations and displacements respectively are presented in Table 4.

The variations in flexibility were not unexpected. Since interior shear walls are associated with a larger proportion of the foundation area than end ones, the interior ones are likely to appear to have stiffer foundations. Also soil stiffness will vary with the extent of over excavation (with the associated consequent increased volume of site concrete) and also the effects of the dewatering process. The translational stiffness will also reflect the degree of compaction and nature of the backfill used.

If it is assumed that the foundation of a structure is rigid and that the normal vertical soil reaction at any point under the base is proportional to the deflection at this point, the applied moment and the rotation of the base are related(9) by

$$
\begin{aligned}
\text { where } & =C_{\mathrm{r}} \cdot \mathrm{I} \cdot \phi \\
\mathrm{C}_{\mathrm{r}} & =\text { coefficient of elastic non- } \\
I & =\text { uniform compression } \\
\phi & =\text { base rotation }
\end{aligned}
$$

Similarly the applied lateral force and displacements of the base are related by

$$
\begin{aligned}
\mathrm{F} & =\mathrm{C}_{t} \cdot \mathrm{A} \cdot \mathrm{S} \\
\text { where } \mathrm{F} & =\text { applied lateral load } \\
\mathrm{C}_{\mathrm{t}} & =\text { coefficient of elastic uniform } \\
& \text { shear } \\
\mathrm{A} & =\text { area of base } \\
\mathrm{S} & =\text { lateral base displacement }
\end{aligned}
$$

The appropriate foundation coefficients derived from the testing of the Zoology building are listed in Table 5 。

\section{CLOSURE}

It is evident that the dynamic properties of buildings such as the one tested can be pre- dicted with reasonable certainty, within tho lower region of the elastic stress-strain curve, provided that satisfactory allowances for foundation compliance are included.

The unusual feature of the dynamic characteristics of the Zoology building is the proportionately large contribution to the lateral displacemont provided by ground flexibility Undoubtedly the results obtained are consistent with the combination of a relativoly stiff structure on a fairly flexible foundation but very few previous investigators have established that foundation compliance can contribute so great a proportion of the total moment of a dynamically loaded building.

\section{Acknowledgements}

The investigation described was facilitated by the unreserved support of the administrative, academic and technical staff of the University of Canterbury and the cooperation of both the Fletcher Construction Company and the Ministry of Works.

The testing comprised part of that undertaken by the first author, as part of his Ph.D studies, under the supervision of the second author.

\section{References}

1. Basic Design Loads。 N.Z.S.S. 1900 Chapter 8, N.Z. Standards Institute 1965。

2. Shepherd, R. and Reay, A. M。 Some Apparatus for the Small Amplitude Dynamic Testing of Multistorey Buildings, Strain, Journal of the British Society Vol。3. No。 4. October 1967.

3. Shepherd, R. Determination of Seismic Design Loads in a Framed Structure New Zealand Engineering, 1967, 22(2), 56-61.

4. Shepherd, R. and Donald, R.A.H. Foundation Deformation Effects in Structural Dynamic Analysis Proceedings, Fifth Australia New Zealand Soil Mechanics Conference, Auckland, 1967, 205-212.

5. Reay, A。 M. Dynamic Characteristics of Civil Engineering Structures. Unpublished Ph.D. Thesis. University of Canterbury 1970 .

6. Den Hartog, J.P. Mechanical Vibrations. McGraw Hill Book Co. Inc. 1947.

7. Nielson, N. N. Dynamic Response of Multistorey Buildings. Earthquake Engineering Research Laboratory, California Institute of Technology, Pasadena, Cal ifornia 1964.

8. Muto, K. Seismic Analysis of Reinforced Concrete Building. Shokoku-Sha Publishing Company, Tokyo, Japan 1965 。

9. Barkan, D. P. Dynamics of Bases and Foundations. McGraw-Hill, New York, 1962 . 
TABLE 1

RESPONSE SEPARATION RESULTS - LONGITUDINAL RESPONSE

\begin{tabular}{|c|c|c|c|c|}
\hline \multirow[b]{2}{*}{$\begin{array}{l}\text { Response } \\
\text { Curve }\end{array}$} & \multicolumn{2}{|c|}{ First Torsional Mode } & \multicolumn{2}{|c|}{ First Longitudinal Mode } \\
\hline & $\begin{array}{c}\text { Natural } \\
\text { Frequency } \\
\text { c.p.s. }\end{array}$ & $\begin{array}{l}\text { Damping } \\
\% \text { e.v. }\end{array}$ & $\begin{array}{l}\text { Natural } \\
\text { Frequency } \\
\text { c.p.s. }\end{array}$ & $\begin{array}{l}\text { Damping } \\
\% \text { e.v. }\end{array}$ \\
\hline Roof & 4.07 & 7.5 & 4.93 & $10 \circ 9$ \\
\hline 4 th Floor & 4.21 & 6.1 & 4.99 & 10.6 \\
\hline 2nd Floor & 4.18 & 6.5 & 4.92 & $9 \cdot 5$ \\
\hline Grd Floor & 4.21 & 7.1 & 4.90 & 9.5 \\
\hline Average & 4.167 & 6.85 & 4.935 & 10.125 \\
\hline
\end{tabular}

TABLE 2

SUMMARY OF EXPERIMENTAL RESULTS

\begin{tabular}{|cccc|}
\hline Mode & $\begin{array}{c}\text { Resonant } \\
\text { Frequency } \\
\text { c.p.s. }\end{array}$ & $\begin{array}{c}\text { Force at } \\
\text { Resonance } \\
\text { 1bs }\end{array}$ & $\begin{array}{c}\text { Damping } \\
\text { e.v. }\end{array}$ \\
\hline 1st Translation & 3.01 & 140 & 4.1 \\
2nd Translation & 11.34 & 1,980 & 6.6 \\
1st Torsional & 4.14 & 264 & 6.9 \\
Roof Slab & 4.93 & 375 & 10.1 \\
\hline
\end{tabular}


TABLE 3

FOUNDATION COMPLIANCE EFFECT

\begin{tabular}{|c|c|c|c|}
\hline Fundamental Mode & \multicolumn{3}{|c|}{$\begin{array}{c}\text { Average component in Roof Deflection } \\
\text { due to Foundation Compliance }\end{array}$} \\
\hline & $\begin{array}{c}\text { Rotation } \\
\%\end{array}$ & $\begin{array}{c}\text { Translation } \\
\%\end{array}$ & $\begin{array}{c}\text { Total } \\
\%\end{array}$ \\
\cline { 2 - 4 } & 27 & 5 & 32 \\
E-W & 10 & 14 & 24 \\
\hline
\end{tabular}

TABLE 4

BASE FLEXIBILITIES - FOR FUNDAMENTAL MODE

\begin{tabular}{|cccc|}
\hline Direction & Element & $\begin{array}{c}\text { Translational } \\
\text { Base Flexibil- } \\
\text { ity } \\
\text { ins/1b x 107 }\end{array}$ & $\begin{array}{c}\text { Rotational } \\
\text { Base Flexibility } \\
\text { radians/1b.in x 10 13 }\end{array}$ \\
\hline E - W & S.W.1 & 0.245 & 1.36 \\
$E-W$ & S.W.3 & 0.100 & 1.08 \\
$E-W$ & $\begin{array}{c}\text { Whole } \\
\text { Structure } \\
\text { Whole } \\
\text { Structure }\end{array}$ & 0.072 & 0.625 \\
& 0.070 & 0.102 \\
\hline
\end{tabular}

TABLE 5

ELASTIC FOUNDATION COEFFICIENTS

\begin{tabular}{|ccc|}
\hline Direction & $\begin{array}{c}\mathrm{C}_{\mathrm{t}} \\
\text { Ibs/in }\end{array}$ & $\begin{array}{c}\mathrm{C}_{\mathrm{r}} \\
\text { lbs } / \mathrm{in}^{3}\end{array}$ \\
\hline $\mathrm{E}-\mathrm{W}$ & 300 & 670 \\
$\mathrm{~N}-\mathrm{S}$ & 245 & 500 \\
\hline
\end{tabular}




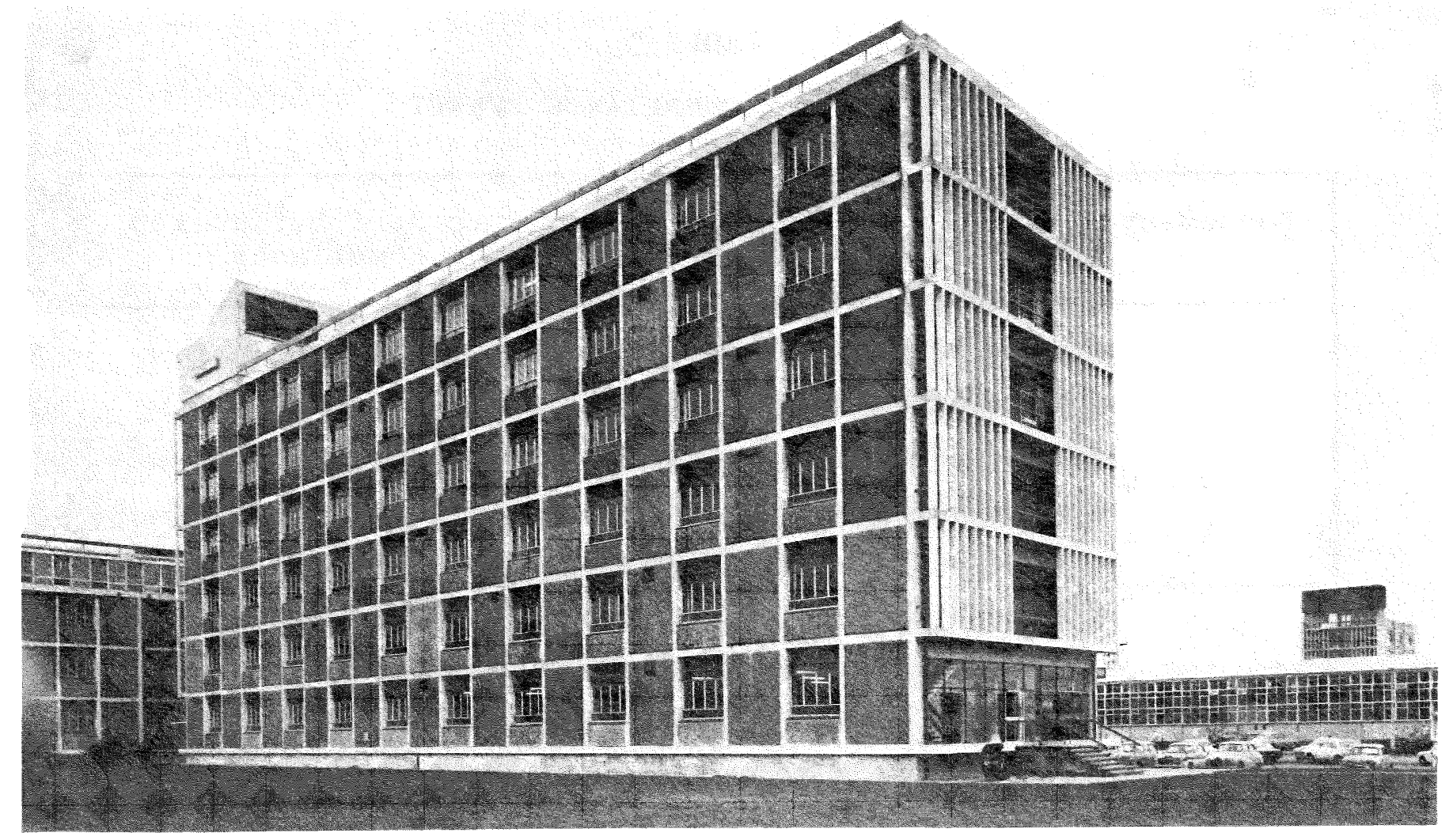

FIG. 1 UNIVERSITY OF CANTERBURY ZOOLOGY BUILDING
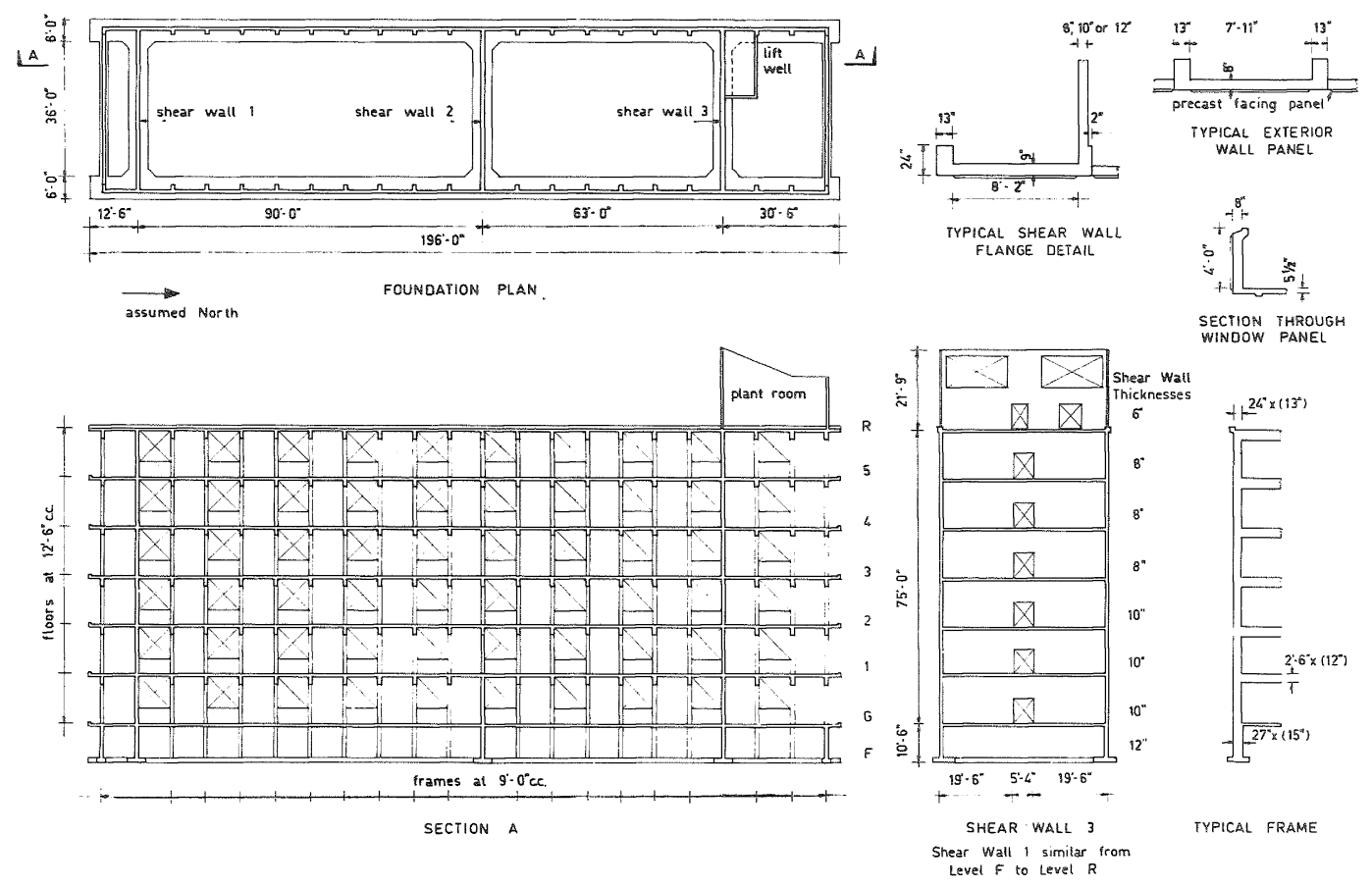

FIG.2 - ZOOLOGY BUILDING - STRUCTURAL LAYOUT 

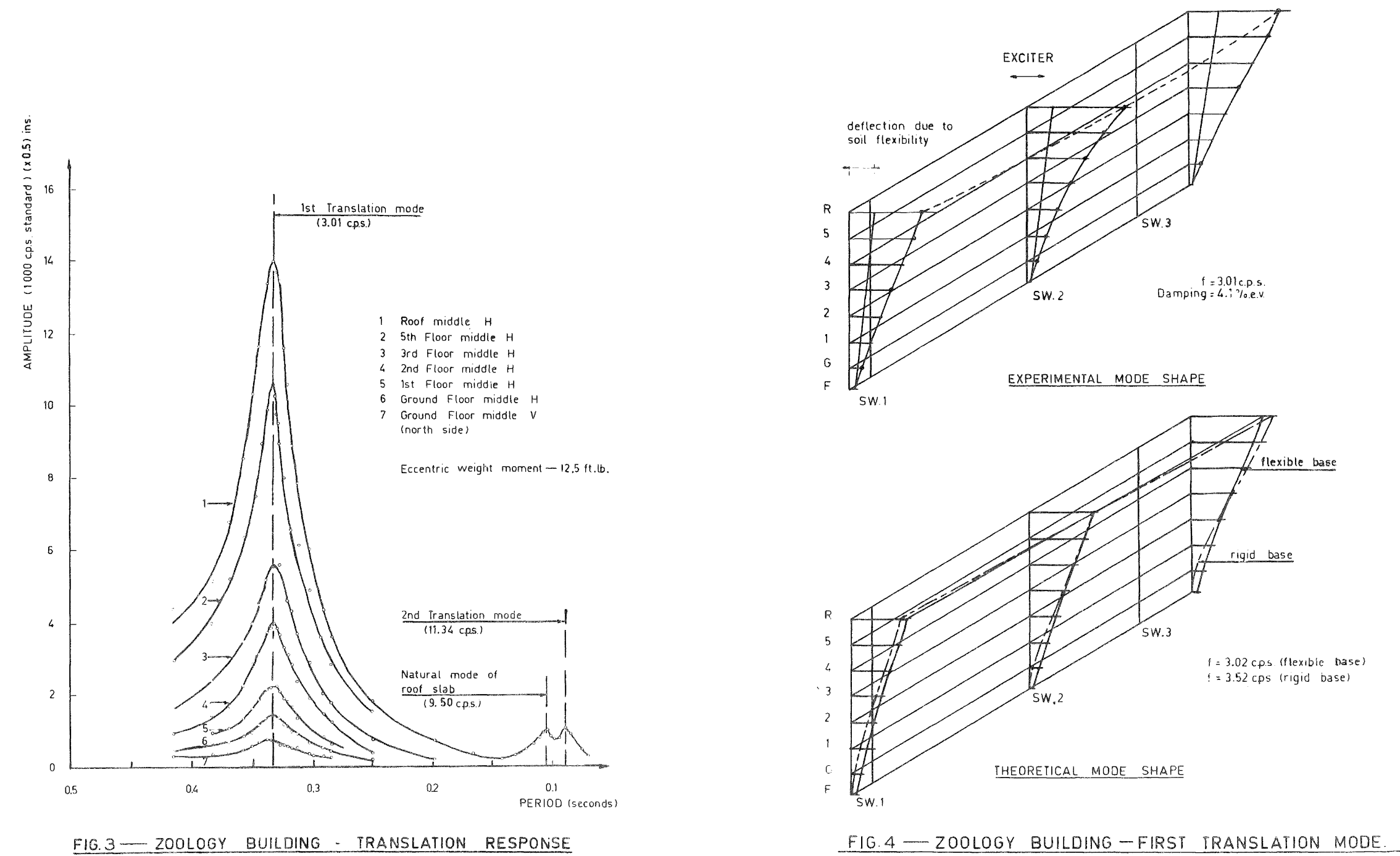

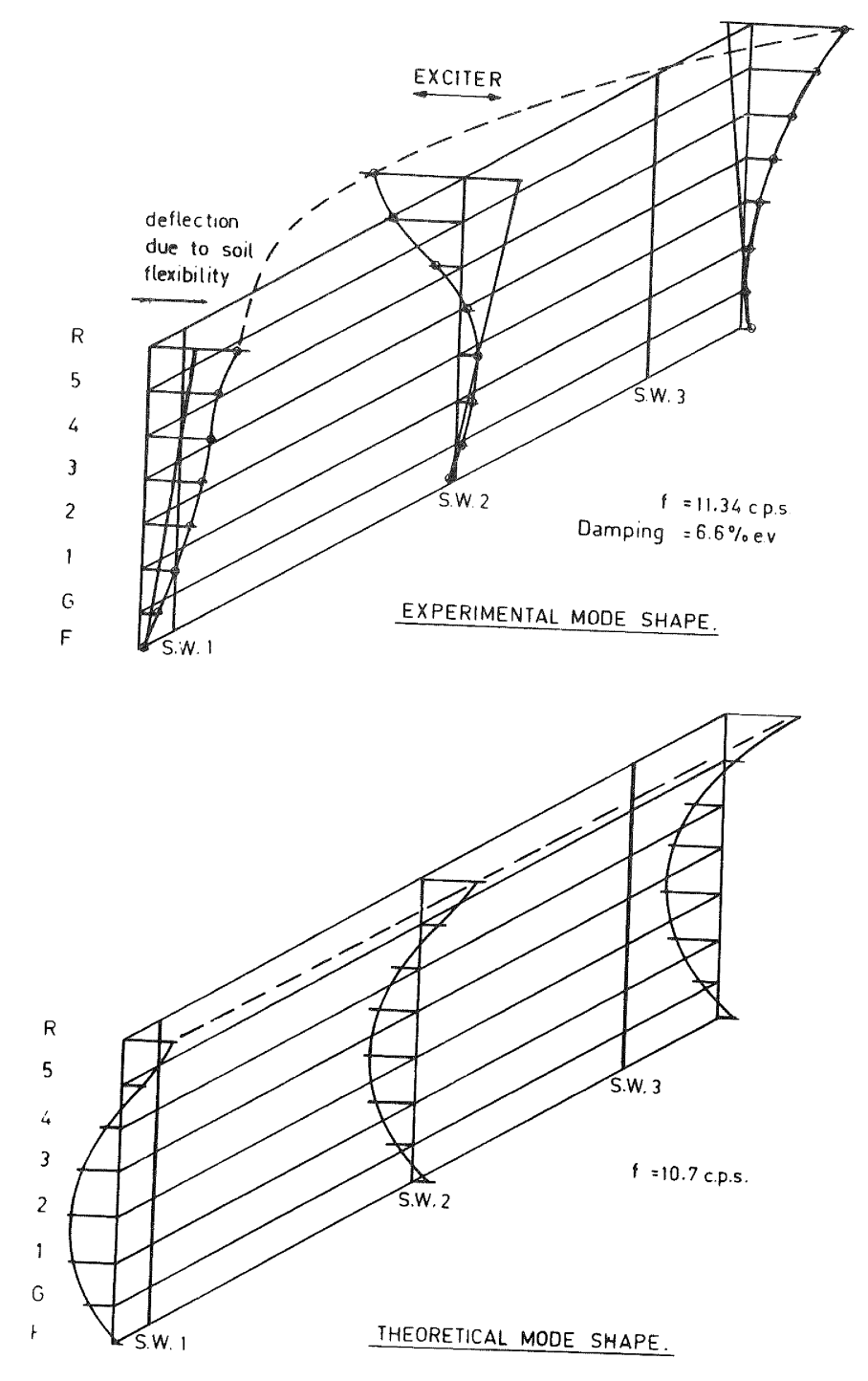

FIG.5-ZOOLOGY BUILDING-SECOND TRANSLATION MODE.

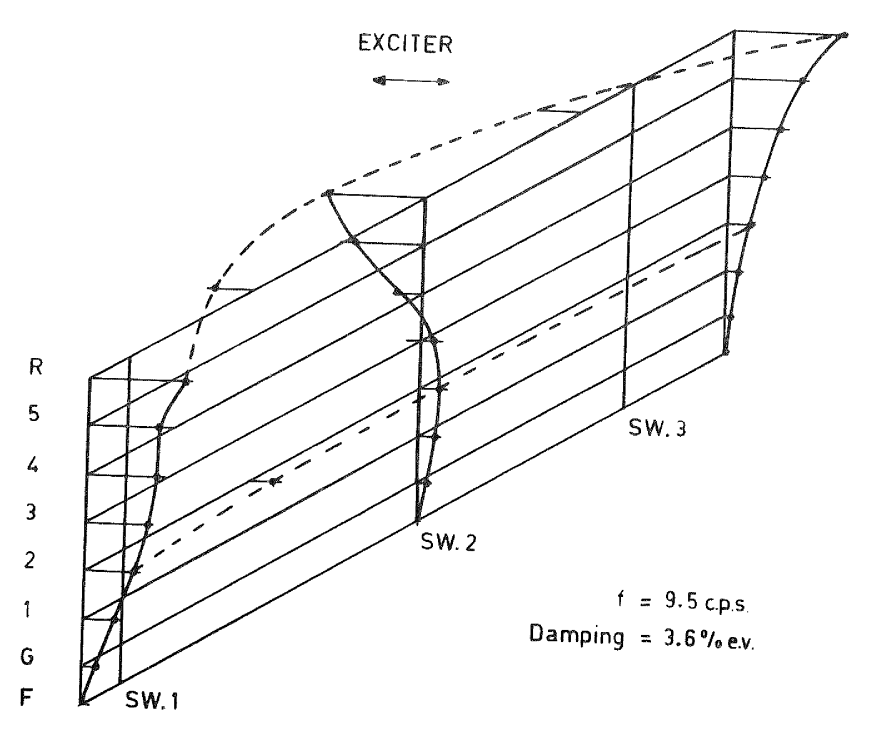

ROOF VIBRATING AS A FREE-FREE BEAM

FIG.6 - ZOOLOGY BUILDING - TRANSLATION RESPONSE 


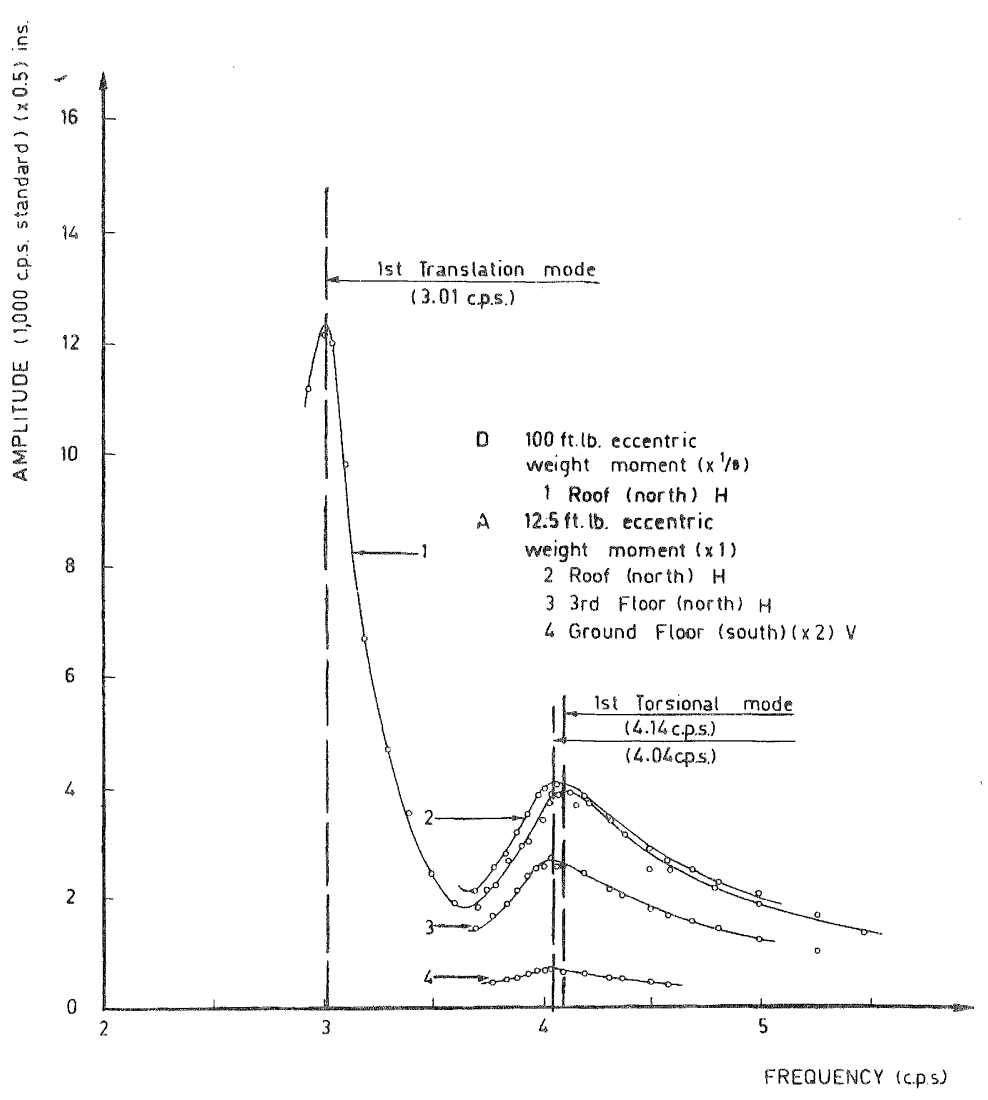

F1G.7 - ZOOLOGY BUILOING - TORSIONAL RESPONSE

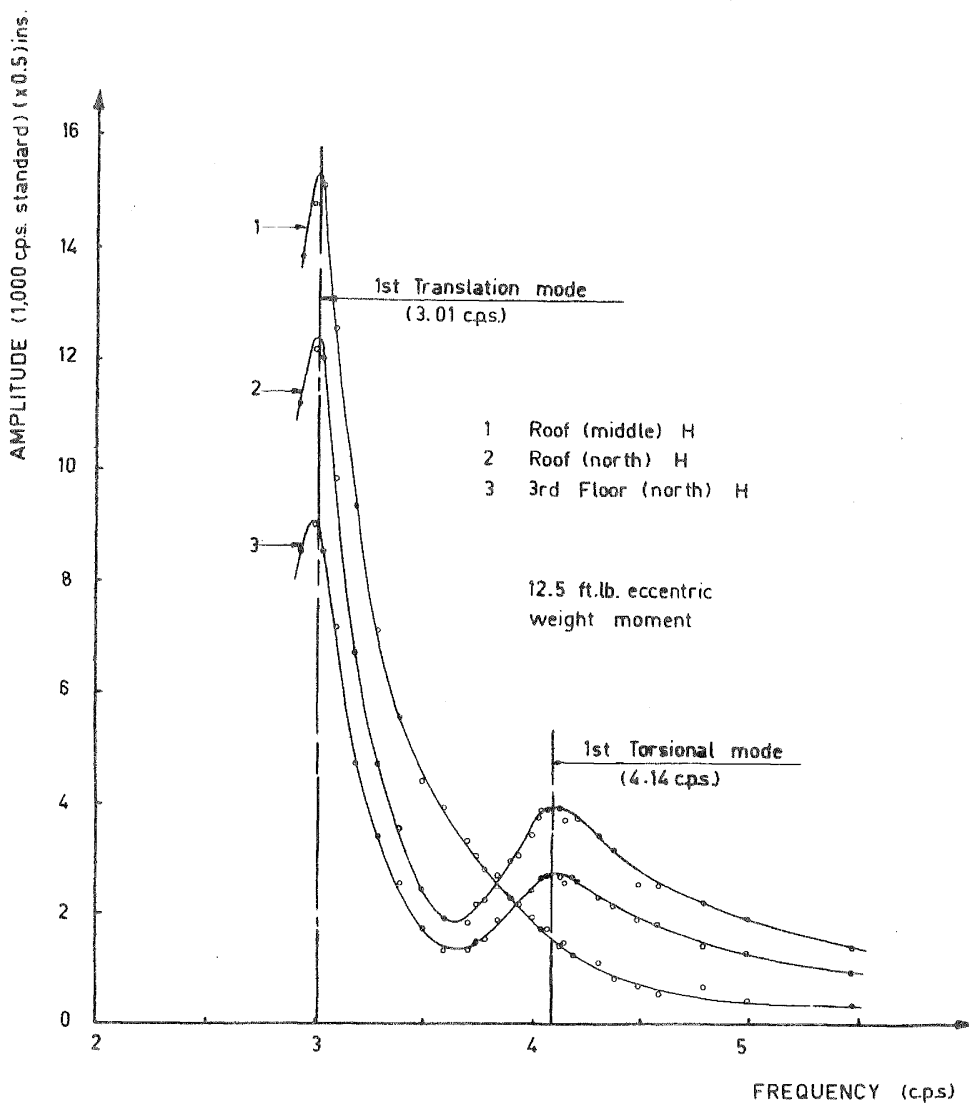

FIG. 8 - ZOOLOGY BUILDING - TORSIONAL RESPONSE. 

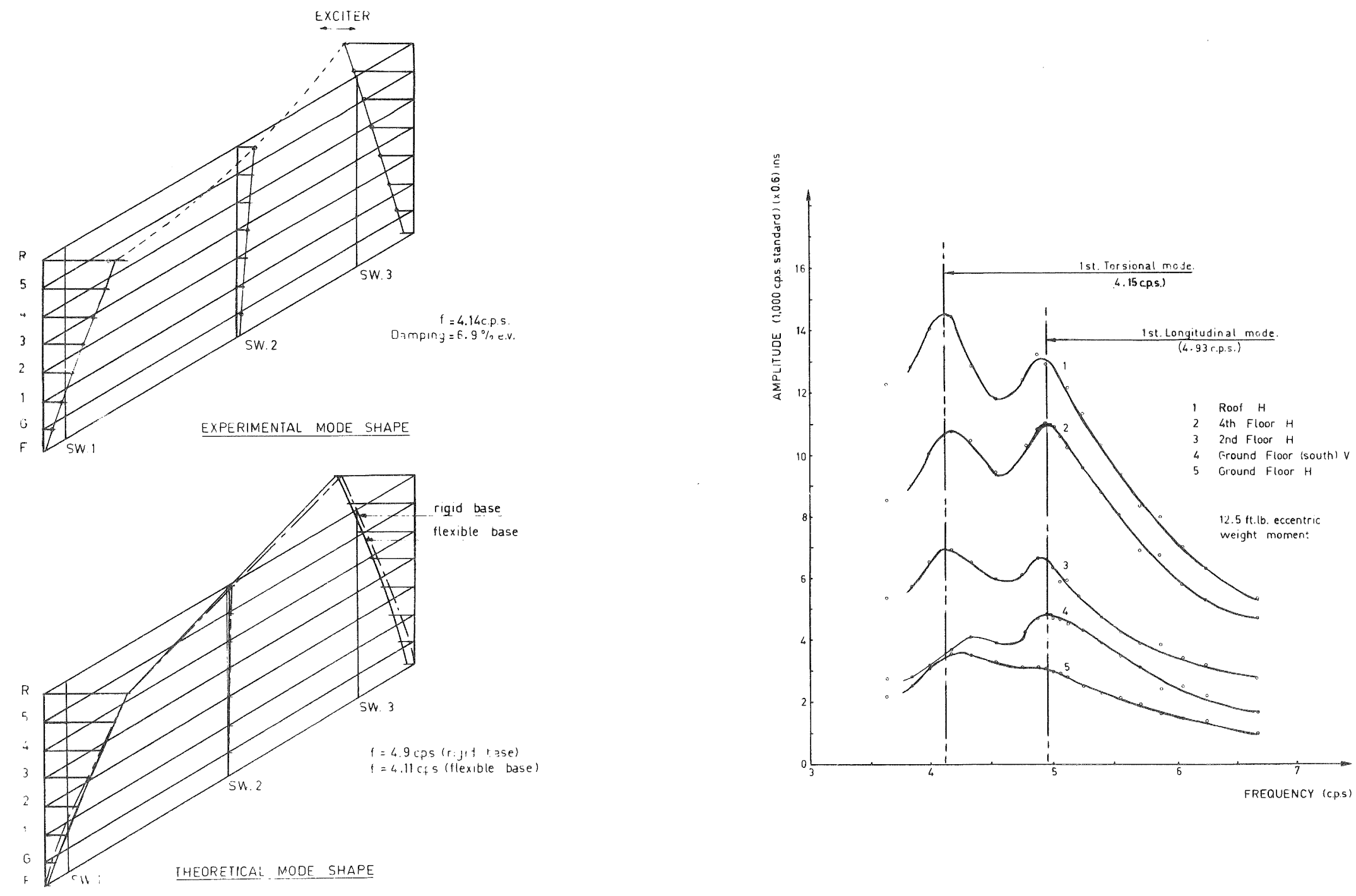

FIG 9-ZOOLOGY BUILDING - FIRST TORSIONAL MODE 


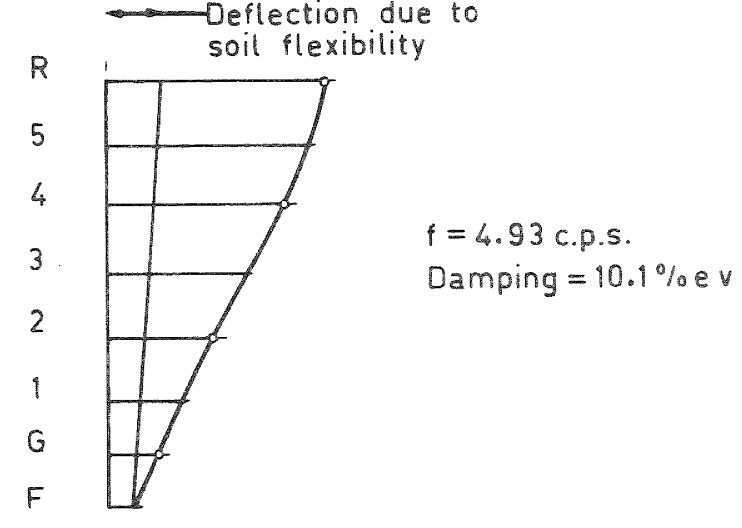

FIRST MODE EXPERIMENTAL

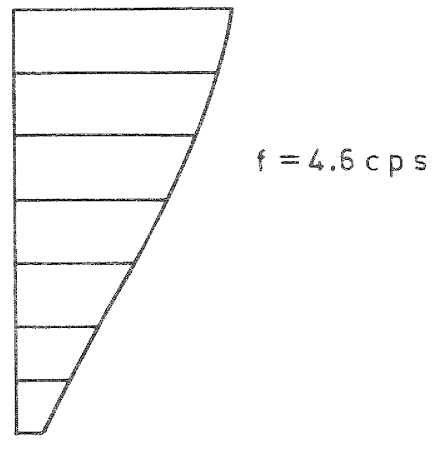

FIRST MODE THEORETICAL

FIG.11-ZOOLOGY BUILDING LONGITUDINAL MODE SHAPES 